\title{
ПОДХОДЫ К ЛЕЧЕНИЮ И ПРОФИЛАКТИКЕ
} ПЕЛЕНОЧНОГО ДЕРМАТИТА

В статье рассматриваются особенности строения и функций кожи детей первого года жизни, причины возникновения пеленочного дерматита. Определен приоритет профилактических мер и выбор оптимального средства для местного применения, которые соответствуют международным стандартам. Подробно описаны требования к наружным средствам, применяемым у детей первого года жизни для профилактики ПД, согласно международному мнению группы экспертов.

Ключевые слова: пеленочный дерматит (ПД), кожа младенцев, наружные средства, лечение и профилактика ПД, декспантенол.

N.M. SHAROVA, N.I.Pirogov Russian National Research Medical University FGBOU VO, Moscow APPROACHES TO TREATMENT AND PREVENTION OF DIAPER DERMATITIS

The article deals with the features of skin structure and functions in infants and the causes of diaper dermatitis. It determined the priority of preventive measures and the choice of optimal agents for topical application that meet international standards. The requirements for topical agents used in infants for prevention of DD are described in detail, according to the international opinion of the experts group.

Keywords: diaper dermatitis (DD), infant skin, topical agents, treatment and prevention of DD, dexapanthenol.

еленочный дерматит - это воспалительные изменения кожи у детей младенческого возраста в области подгузников. Наблюдается приблизительно у 50\% детей первого года жизни. Наиболее часто ПД возникает в возрасте от 6 до 12 месяцев. По данным некоторых авторов [1-4], у 50\% детей дерматит протекает в легкой форме, у 20\% младенцев развивается среднетяжелая и лишь у 5\% - тяжелая форма дерматита.

Функциональное состояние и особенности структуры кожи детей первого года жизни предрасполагают к развитию воспалительных изменений. С другой стороны, такие факторы, как повышенная влажность, мацерация, контакт с мочой и калом, являются негативными в отношении барьерной функции кожи. Использование мыла и моющих средств без учета возрастных особенностей кожи, лекарственных средств, в частности антибиотиков, аллергические реакции на местные препараты или компоненты подгузника также являются факторами, приводящими к воспалительным изменениям в этой зоне у детей. В отношении проявлений ПД определен стандарт, способствующий уменьшению воспаления и защите от действия причинных факторов. Разнообразные средства для предотвращения и борьбы с воспалением в области подгузников иногда могут усугубить течение патологического процесса и вызывать аллергические реакции из-за содержания химических компонентов. Важно понимать, что некоторые препараты для лечения ПД не могут быть использованы для оптимальной профилактики воспаления в зоне подгузников.

\section{ОСОБЕННОСТИ СТРОЕНИЯ И ФУНКЦИЙ КОЖИ МЛАДЕНЦЕВ}

Структура кожи новорожденных и детей до 12 месяцев имеет некоторые отличия от структуры кожи детей старше 12 месяцев. Эпидермис более тонкий, а роговой слой на 30\% тоньше по сравнению с более старшим возрастом.
Важным отличием является высокая скорость пролиферации кератиноцитов, однако связь между клетками более слабая, что определяет легкую ранимость, высокую чувствительность к раздражителям и повышенную абсорбцию. Трансэпидермальная потеря воды несколько выше у детей первого года жизни, обеспечивает поддержание увлажненности кожного покрова. При рождении $\mathrm{pH}$ кожи ниже, чем в более старшем возрасте, что способствует синтезу липидов в ламеллярных пластах и последующему созреванию рогового слоя. Эти особенности кожи детей первых месяцев жизни не позволяют полностью противостоять действию различных раздражающих факторов $[5,6]$.

\section{ПРИЧИНЫ ПЕЛЕНОЧНОГО ДЕРМАТИТА}

Пеленочный дерматит развивается под воздействием комплекса различных факторов [7]. Наибольшее значение имеет длительный контакт кожи с мочой и калом. Мацерация кожи возникает в условиях повышенной влажности.

Разнообразные средства для предотвращения и борьбы с воспалением в области подгузников иногда могут усугубить течение патологического процесса и вызывать аллергические реакции из-за содержания химических компонентов. Важно понимать, что некоторые препараты для лечения ПД не могут быть использованы для оптимальной профилактики воспаления в зоне подгузников

При этом происходит не только разрыхление рогового слоя, но и экстракция липидов и естественных увлажняющих факторов, таким образом, нарушается кожный барьер, он становится проницаемым для различного рода раздражителей [8]. В то же время сдвиг рН в щелочную сторону, воздействие фекальных пищеварительных ферментов 


\section{Таблица 1. Стандарты идеального средства для лечения пеленочного дерматита}

\begin{tabular}{|c|c|}
\hline \multirow{9}{*}{$\begin{array}{l}\text { Свойства } \\
\text { идеального } \\
\text { средства } \\
\text { для местного } \\
\text { применения } \\
\text { при ПД }\end{array}$} & $\begin{array}{l}\text { Обладает подтвержденной клинической эффективностью } \\
\text { и безопасностью при применении у младенцев }\end{array}$ \\
\hline & Усиливает естественную защиту кожи \\
\hline & Поддерживает оптимальный уровень увлажненности \\
\hline & Содержит достоверно безопасные и полезные ингредиенты \\
\hline & Не содержит лишних ингредиентов \\
\hline & Не содержит потенциально токсичных ингредиентов \\
\hline & Не содержит потенциальных аллергенов (отдушек) \\
\hline & Не содержит антисептиков и консервантов \\
\hline & Удобен в использовании \\
\hline
\end{tabular}

способствуют развитию воспалительной реакции. Дополнительным фактором явлений воспаления является механическое трение мацерированного рогового слоя (рис.).

В результате взаимодействия мочи с уреазами кала происходит образование аммиака и сдвиг рН в щелочную сторону, что, в свою очередь, активирует фекальные протеазы и липазы, которые расщепляют липиды и белковые структуры рогового слоя кожи с развитием раздражения.

Риск развития ПД может повышаться при использовании влажных салфеток, очищающих средств, содержащих отдушки, консерванты, за счет разрушения липидов поверхности кожи [9]. Повышенная проницаемость кожи для аллергенов стимулирует развитие иммунных реакций и аллергического воспаления [10]. Изучение механизмов ПД показало, что бактерии/ грибы не участвуют в формировании воспалительной реакции, однако при системном применении антибиотиков и повышении рН могут способствовать вторичному инфицированию на фоне развившегося ПД, и в результате нарушения нормальной флоры создаются условия для колонизации условно-патогенными Candida albicans $[11,12]$.

\section{ПРОФИЛАКТИКА И ЛЕЧЕНИЕ ПЕЛЕНОЧНОГО ДЕРМАТИТА}

Алгоритм лечебных и профилактических мероприятий включает A (Air) - аэрацию, доступ воздуха, В (Barrier) восстановление и поддержание барьерной функции кожи (защитные средства, в составе которых имеются регенерирующие и противовоспалительные компоненты), C (Cleaning) - очищение, D (Diaper) - использование подгузников и пеленок, E (Education) - обучение, просвещение родителей [13].

Для очищения зоны подгузников от мочи и кала необходимо использовать мягкие моющие средства, предназначенные для бережного удаления раздражителей, способные поддерживать $\mathrm{pH}$ кожи и сохраняющие липиды поверхности [14]. После смывания ирритантов кожу необходимо высушить, не допуская трения.

\section{Риск развития ПД может повышаться при использовании влажных салфеток, очищающих средств, содержащих отдушки, консерванты, за счет разрушения липидов поверхности кожи}

Необходимо регулярно менять подгузники, минимизировать контакт кожи с мочой/калом. В настоящее время подгузники содержат абсорбирующие компоненты, поддерживающие кожу в оптимальном состоянии.

Особое внимание необходимо уделять защитным наружным средствам для профилактики и лечения ПД, учитывая основные критерии их состава и воздействия на кожу младенцев. Благодаря работе международной экспертной группы дерматологов в 2015 г. были определены и согласованы 9 стандартов, которым должно соответствовать идеальное защитное средство для профилактики ПД (табл. 1) [15-17].

\section{Состав}

Не рекомендуется применять средства, содержащие антисептики, т. к. они могут нарушать нормальную естественную микробную флору.

\section{Рисунок. Факторы, приводящие к ПД}

\section{1. Длительный контакт кожи с мочой и калом \\ 2. Повышенная влажность и рH}

\section{Нарушение} защитной функции кожи

Высокая проницаемость, всасываемость
- Мацерация рогового слоя

- Значительные нарушения в липидном слое 


\section{Свойства}

Защитные наружные средства должны обладать увлажняющими свойствами, защищать и поддерживать барьерную функцию кожи, способствовать стимулированию регенерации.

Хорошо зарекомендовали себя такие вещества, как декспантенол, никотинамид, фосфолипиды, входящие в состав средств для местного применения в лечении и профилактике ПД. Их действие усиливает образование собственных липидов, уменьшает признаки раздражения, восстанавливает кожный барьер и ограждает от действия раздражающих факторов внешней среды. Повышение синтеза собственных липидов - важный положительный эффект, т. к. многие кремы и мази содержат различные церамиды и лишь имитируют естественный состав липидов кожи $[18,19]$.

\section{Форма}

Баланс между ТЭПВ и всасыванием воды через поверхность кожного покрова определяет степень увлажненности. При использовании наружных средств важно, чтобы они не создавали непроницаемую пленку (окклюзию), а способствовали нормальному испарению воды с поверхности и не меняли местного $\mathrm{pH}$.

Наиболее оптимальными наружными формами для младенцев являются эмульсии по типу «вода в масле» (например, мазь Бепантен), поскольку они сохраняют липидный барьер, защищают кожу от различного раздражения и препятствуют значимой потере влаги. Другие формы наружных средств (пасты на водной или жировой основе) обладают выраженными окклюзионными свойствами, мацерируют роговой слой, вследствие чего не могут применяться для ежедневной профилактики ПД (табл. 2). Присыпки также не рекомендуются для постоянного применения, так как не поддерживают непрерывный защитный барьер на коже и обладают абразивными свойствами [20].

\section{Эффективность и безопасность}

В рекомендациях отмечается необходимость тестирования на эффективность и безопасность средств для местного применения у детей младше 3 лет, даже если продемонстрирована безопасность отдельных компонентов косметического средства.

\section{Таблица 2. Свойства наружных форм}

\begin{tabular}{l|l|l|l} 
Паста & $\begin{array}{l}\text { Порошкообразные } \\
\text { вещества }\end{array}$ & $\begin{array}{l}\text { Слабо гидрофильны или } \\
\text { крайне липофильны } \\
\text { в зависимости от основы }\end{array}$ & $\begin{array}{l}\text { Создают недостаточную или } \\
\text { чрезмерную окклюзию } \\
\text { Не подходят для } \\
\text { ежедневного применения }\end{array}$ \\
\hline Мазь/вазелин & Жир & $\begin{array}{l}\text { Препятствует испарению } \\
\text { воды, мацерирует роговой } \\
\text { слой }\end{array}$ & $\begin{array}{l}\text { Создает окклюзию } \\
\text { Не подходит для } \\
\text { ежедневного применения }\end{array}$ \\
\hline $\begin{array}{l}\text { Эмульсия } \\
\text { «масло в воде» }\end{array}$ & Липидов $\leqslant 50 \%$ & $\begin{array}{l}\text { Слабая способность создавать } \\
\text { эффективный барьер }\end{array}$ & $\begin{array}{l}\text { Не подходит для } \\
\text { ежедневного применения }\end{array}$ \\
\hline $\begin{array}{l}\text { Эмульсия } \\
\text { «вода в масле» }\end{array}$ & Липидов $\geqslant 50 \%$ & $\begin{array}{l}\text { «Дышащая» защита, } \\
\text { сохраняющая естественный } \\
\text { уровень увлажненности кожи }\end{array}$ & $\begin{array}{l}\text { Наиболее подходящая } \\
\text { форма для ежедневного } \\
\text { применения }\end{array}$
\end{tabular}

Достоверно безопасные и полезные ингредиенты декспантенол и фосфолипиды являются главными компонентами, обеспечивающими увлажнение и защиту кожи; витамин $B_{3}$ подавляет активность фекальных ферментов и препятствует повышению $\mathrm{pH}$. Имеются доказательства того, что ланолин препятствует развитию инфекции [21].

В одной из зарубежных публикаций [22] подводится итог 70-летнего использования декспантенол-содержащей формулы, способствующей увлажнению и поддержанию кожного барьера. Обнаружено, что декспантенол повышает активность молекулярных компонентов клеток рогового слоя, модулирует экспрессию генов, регулирующих репарацию, что в конечном итоге нормализует барьерную функцию кожи [23]. На протяжении длительного времени изучается не только клиническая эффективность этих средств, но и влияние на молекулярно-генетические аспекты воспалительной реакции. В экспериментаx in vitro демонстрируется влияние декспантенола на пролиферацию дермальных фибробластов и экспрессию генов CYP1B1, CXCL1, CCL18, сар4-2, играющих важную роль в воспалении и последующей репарации [24].

\section{Защитные наружные средства должны обладать увлажняющими свойствами, защищать и поддерживать барьерную функцию кожи, способствовать стимулированию регенерации. Хорошо зарекомендовали себя такие вещества, как декспантенол, никотинамид, фосфолипиды, входящие в состав средств для местного применения в лечении и профилактике ПД}

В составе наружных средств для профилактики ПД у младенцев не должно содержаться лишних ингредиентов. Отсутствуют доказательства пользы и эффективности для профилактики ПД витамина А, борной кислоты, которые нередко включают в местно применяемые средства $[25,26]$.

Высокая абсорбционная способность кожи младенцев диктует необходимость контролировать наличие потенциально токсических и аллергенных веществ (например, борная кислота), отдушек (например, бензиловый спирт, бензилбензоат) и др.

Нет необходимости включать в состав средств для профилактики ПД антисептики из-за отсутствия данных, указывающих на роль в патогенезе ПД микроорганизмов. Напротив, антисептики могут нарушать нормальный состав микрофлоры и повышать риск развития вторичного инфицирования.

\section{Комплаенс (удобство в использовании)}

По мнению экспертов, необходимо повышать информированность родителей о новейших достижениях в технологии изготовления подгузников, средств по уходу за кожей младенцев и использовании безопасных и эффек- 
тивных топических средств с профилактической целью ПД. Важно соблюдать гигиенические правила и применять удобные формы наружных средств в виде эмульсий («масло в воде»), не требующих дополнительного очищения кожи при смене подгузников.

\section{ЗАКЛЮЧЕНИЕ}

Особенности строения кожи младенцев, склонной к мацерации, травматизации и воспалительным реакциям, диктуют тщательное отношение к выбору средств лечения и профилактики ПД. Воспаление возникает при условии взаимодействия мочи и кала, активации ферментов кала, образовании аммиака и разрушении кожного барьера. Приоритетом современной тактики ухода за младенцами становится профилактика ПД благодаря использованию средств, содержащих безопасные и эффективные компоненты. Наружные средства для профилактики и лечения ПД должны соответствовать основным требованиям согласно международной экспертной оценке: клинически протестированы, усиливать естественную защиту кожи, поддерживать оптимальный уровень ее увлажнения, не содержать токсических веществ, аллергенов, консервантов, парабенов, отдушек, антисептиков и быть удобными в использовании при регулярном применении. Эти стандарты должны служить ориентиром для применяемых сегодня средств в уходе за детьми при ПД и при разработке средств следующих поколений. Следует отметить, что современным представителем наружного средства по уходу за детьми, страдающими ПД, в соответствии с принятыми стандартами является оригинальный препарат на основе декспантенола Бепантен мазь.

\section{Необходимо повышать информированность родителей о новейших достижениях в технологии изготовления подгузников, средств по уходу за кожей младенцев и использовании безопасных и эффективных топических средств с профилактической челью ПД}

Препарат не содержит консервантов, отдушек и красителей, а в его состав включены вещества с доказано высокой степенью безопасности - декспантенол, ланолин, миндальное масло и липиды, эффективно защищающие кожу от раздражителей и способствующие регенерации.

\section{Конфликт интересов: автор заявляет об отсутствии} конфликта интересов в ходе написания данной статьи.

\section{ЛИТЕРАТУРА}

1. Nikolovski J, Stamatas GN, Kollias N, Wiegand $\mathrm{BC}$. Barrier function and water-holding and transport properties of infant stratum corneum are different from adult and continue to develop through the first year of life. J Invest Dermatol, 2008, 128: 1728-1736.

2. Stamatas GN, Nikolovski J, Luedtke MA, Kollias $\mathrm{N}$, Wiegand BC. Infant skin microstructure assessed in vivo differs from adult skin in organization and at the cellular level. Pediatr Dermatol, 2010, 27: 125-131.

3. Hoeger PH, Enzmann CC. Skin physiology of the neonate and young infant: a prospective study of functional skin parameters during early infancy. Pediatr Dermatol, 2002, 19: 256-262.

4. Василевский И.В. Оптимизация ухода за кожей у новорожденных и детей грудного возраста. Международные обзоры: клиническая практика и здоровье, 2015, 1: 5-18./ Vasilevsky IV. Optimization of skin care in newborns and infants. Mezhdunarodnye Obzory: Klinicheskaja Praktika i Zdorovye, 2015, 1: 5-18.

5. Jordan WE, Lawson KD, Berg RW, Franxman JJ, Marrer AM. Diaper dermatitis: frequency and severity among a general infant population. Pediatr Dermatol, 1986, 3: 198-207.

6. Мурашкин Н.Н., Материкин А.И., Епишев Р.В., Амбарчан Э.Т. Особенности течения и профилактики пеленочного дерматита у новорожденных и грудных детей. Вопросы современной педиатрии, 2015, 14(6): 710-713. / Murashkin NN, Materikin Al, Epishev RV, Ambarchan ET. Features of the course and prevention of diaper dermatitis in newborns and infants. Voprosy Sovremennoy Pediatrii, 2015, 14 (6): 710-713.
7. Atherton DJ.A review of the pathophysiology, prevention and treatment of irritant diaper dermatitis. Curr Med Res Opin, 2004, 20: 645-649.

8. Warner RR, Stone KJ, Boissy YL. Hydration disrupts human stratum corneum ultrastructure. J Invest Dermatol, 2003, 120: 275-284.

9. Horowitz P, McLeod RP, Eichenfield LF, Fowler JF, Jr., Elias PM. Skin-cleansing and care principles for special pediatric populations. Semin Cutan Med Surg, 2013, 32: 30-32.

10. Stamatas GN, Tierney NK. Diaper dermatitis: etiology, manifestations, prevention, and management. Pediatr Dermatol, 2014, 31: 1-7.

11. Atherton D, Mills K. What can be done to keep babies' skin healthy? RCM Midwives, 2004, 7: 288-290.

12. Lund C, Kuller J, Lane A, Lott JW, Raines DA. Neonatal skin care: the scientific basis for practice. J Obstet Gynecol Neonatal Nurs, 1999 28: 241-254

13. Telofski LS, Morello AP, III, Mack Correa MC, Stamatas GN. The infant skin barrier: can we preserve, protect, and enhance the barrier? Dermatol Res Pract, 2012, 2012: 198789.

14. Adam R. Skin care of the diaper area. Pediatr Dermatol, 2008, 25: 427-433.

15. The European Parliament. Regulation (EC) No $1223 / 2009$ of The European Parliament and of The Council On Cosmetic Products. 2009. 1223/2009.

16. National Institute for Health and Care Excellence. Available at: http: //cks.nice.org.uk/ nappy-rash\#!topicsummary. (Last accessed 30 January 2014).

17. Atherton D, Proksch E, Schauber J, Stalder J-F. Irritfnt diaper dermatitis: best practice management. SelfCare, 2015, 6(s1): 1-11.

18. Hoeger PH, Schreiner V, Klaassen IA et al. Epidermal barrier lipids in human vernix caseo- sa: corresponding ceramide pattern in vernix and fetal skin. Br J Dermatol, 2002, 146: 194-201.

19. Proksch E, Nissen HP. Dexpanthenol enhances skin barrier repair and reduces inflammation after sodium lauryl sulphateinduced irritation. J Dermatolog Treat, 2002, 13: 173-178.

20. Одинаева Н.Д., Беляева И.А., Яцык Г.В. Профилактические и лечебные средства для ухода за кожей недоношенных детей. Педиатрическая фармакология, 2009, 6(6): 118-120./ Odinaeva ND, Belyaeva IA, Yatsyk GV. Prophylactic and therapeutic agents for skin care of premature babies. Pediatricheskaya Farmakologiya, 2009, 6 (6): 118-120.

21. Putet G, Guy B, Andres P et al. Effect of Bepanthen ointment in the prevention and treatment of diaper rash on premature and full-term babies. Réalités Pédiatriques, 2001, 63: 33-38.

22. Prokch E, de Bony R, Trapp S, Boudon S. Topical use of dexpanthenol: a 70 th anniversary article. J Dermatolog Treat, 2017 Dec, 28(8): 766-773.

23. Heise R, Skazik C, Marquardt Y, Czaja K et al. Dexpanthenol modulates gene expression in skin wound healing in vivo. Skin Pharmocol Physiol, 2012, 25(5): 241-8.

24. Wananukul S, Limpongsanuruk W, Singalavanija S, Wisuthsarewong W. Comparision of dexpanthenol and zinc oxide ointment base in the treatment of irritant diaper dermatitis from diarrhea: a multicenter stady. J Med Assoc Thai, 2006 Oct, 89(10): 1654-8.

25. See AS, Salleh AB, Bakar FA et al. Risk and Health Effect of Boric Acid. American Journal of Applied Sciences, 2010, 7: 620-627.

26. Davies MW, Dore AJ, Perissinotto KL. Topical vita$\min \mathrm{A}$, or its derivatives, for treating and preventing napkin dermatitis in infants. Cochrane Database Syst Rev, 2005, 2005: CD004300.

\section{СВЕДЕНИЯ ОБ АВТОРЕ:}

Шарова Наталья Михайловна - профессор кафедры дерматовенерологии педиатрического факультета ФГБОУ ВО «Российский национальный исследовательский медицинский университет им. Н.И. Пирогова» Минздрава России, Москва 